\title{
3D CBCT Superimposition Use in Evaluation of Simple Bone Cyst Lesion Resolution-A Case Report
}

\author{
David Dano*, Monica Schmidt, Dhurata Shosho and Anthony Mecham \\ Henry M Goldman School of Dental Medicine, Boston University, USA
}

\begin{abstract}
The simple bone cyst (SBC) is a non-neoplastic osseous lesion mainly diagnosed in young adults, most commonly detected during the second decade of life.

Although there is a clear lack of understanding concerning the etiopathogenesis of the lesion, it is typically present radiographically as a unilocular radiolucent area with a cortical margin of varying thickness and a scalloped border. Adjacent teeth, often canine to the third molar, will be unaffected with their PDLs completely intact. In this case report, a well-documented clinical case was analyzed utilizing radiographic superimposition of cone beam computed tomography $(\mathrm{CBCT})$ scans to demonstrate the initial presentation and subsequent consolidation of the SBC in a 14-year old healthy female patient
\end{abstract}

Keywords: CBCT; Simple bone Cyst; Mandible; lesion

\section{Introduction}

The simple bone cyst (SBC) is an asymptomatic lesion, often accidentally discovered during routine radiological examination. It is a non-neoplastic osseous lesion first described by Lucas and Blum in 1992 [1-3]. In 1946, diagnostic criteria specified the absence of epithelial lining and a bony wall surrounding the lesion as characteristics specific to the SBC [4-11]. Ninety percent of SBC cases are reported to be in long bones such as the proximal humerus and femur, however, simple bone cysts only comprise one percent of all cysts affecting the jaw [7].

Relative to the craniofacial complex, SBCs have been reported to involve the ramus, symphysis, and most commonly, the body of the mandible [12-16]. Pathogenesis of the lesion is unclear as evidenced by the variety of names describing it throughout the literature: idiopathic bone cavity, solitary bone cyst, extravasation cyst, hemorrhagic bone cyst, progressive bone cavity, and unicameral bone cyst are terms used to describe the same lesion $[17,18]$.

There is a clear lack of understanding concerning the etiopathogenesis of SBCs and the literature is replete with etiological theories. The three predominating hypotheses include (a) an abnormality of osseous growth, (b) tumor degeneration, and (c) trauma induced intraosseous hematoma formation followed by enzymatic destruction of adjacent bone [15].

Commonly, though, SBC's are detected during the second decade of life, while some sources report no predilection for male or female, others report a male predominance $[5,6,17]$. Radiographically, the lesion appears as a unilocular, radiolucent image, with a cortical margin of varying thickness. It tends to have a thick, well-established cortex in the alveolar process around the teeth and a faint, or non-existent cortex along the lateral borders and at the apical extent of the lesion $[13,17]$. It is commonly presented with an irregular or scalloped border, which does not affect the lamina dura or roots of the involved or adjacent teeth $[14,17]$. Differential diagnoses should include odontogenic keratocyst, ameloblastoma, central giant cell lesion, central ossifying fibroma, vascular lesions, and adenomatoid odontogenic tumor $[2,5,13,17]$.

Following radiographic diagnosis, conventional treatment requires surgical exploration under local anesthesia and curettage of the bony walls. Definitive diagnosis is achieved during this surgery when the empty cavity is discovered to lack an epithelial lining [18]. Bright blood or a serosanguinous fluid may be aspirated from the cyst cavity, although in scant amounts with minimal yield of specimen for biopsy [18]. Spontaneous resolution has been reported [12,17], however, curettage eliciting fresh blood and subsequent clot formation will yield predictable consolidation. Within six to twelve months after surgical exploration, remineralization of the lesion and normal radiographic appearance will be observed [3].

\section{Case Presentation}

A 14-year-old healthy female presented for a consult due to a random radiographic finding in the right inferior portion of the anterior mandible on a panoramic radiograph taken as part of her orthodontic treatment. Patient reported no symptoms and denied any trauma to the mandible.

Upon clinical examination: no extra oral swelling or lymphadenopathy found, intra oral exam revealed no fluctuation, no buccal or lingual cortical expansion (Figures 1A and 1B), all mandibular canines, lateral and central incisors showed normal response to thermal (cold) test and diagnosed vital with no evidence of mobility and had normal probing depths.

As demonstrated in Figure 2 from a pre-operative CBCT taken on 2014 there is a well-defined, round, lightly corticated mixed-density lesion in the right inferior portion of the anterior mandible. The right border of the lesion lies immediately apical to tooth \#27 and the left border just crosses the midline. It slightly thins but does not expand not perforate the buccal or lingual cortices. It has no effect on the nearby dentition, abutting the apical lamina dura of tooth \#27 without perforation. The internal structure of the lesion is largely hypodense with a mixed, cloudy hyperdensity in the inferior quarter of the lesion.

*Corresponding author: David Dano, DMD, CAGS, Boston University Henry M Goldman School of Dental Medicine Boston, MA, United States, Tel: +1 617-3532000; E-mail: danodavid@gmail.com

Received October 05, 2017; Accepted November 02, 2017; Published November 09, 2017

Citation: Dano D, Schmidt M, Shosho D, Mecham A (2017) 3D CBCT Superimposition Use in Evaluation of Simple Bone Cyst Lesion Resolution-A Case Report. Dentistry 7: 462. doi:10.4172/2161-1122.1000462

Copyright: ( 2017 Dano D, et al. This is an open-access article distributed under the terms of the Creative Commons Attribution License, which permits unrestricted use, distribution, and reproduction in any medium, provided the original author and source are credited. 
Citation: Dano D, Schmidt M, Shosho D, Mecham A (2017) 3D CBCT Superimposition Use in Evaluation of Simple Bone Cyst Lesion Resolution-A Case Report. Dentistry 7: 462. doi:10.4172/2161-1122.1000462

The shape, lack of expansion or effect on other structures, and the appearance of the borders are all suggestive of a simple bone cyst. The internal hyperdensities could be a result of spontaneous healing and bone formation within the lesion.

Following the CBCT findings, exploratory surgery was performed under local anesthesia and $\mathrm{N} 2 \mathrm{O}$ sedation.
Bi lateral mental block anaesthesia with additional local infiltration given followed by sub-marginal flap extending from the mesial aspect of mandibular lateral incisor to the mesial aspect of the lower right mandibular canine (Figure 3A). Full thickness mucoperiostal flap raised, an area mesial to root of the right mandibular canine was identified from the pre-operative imaging to be part of the defined

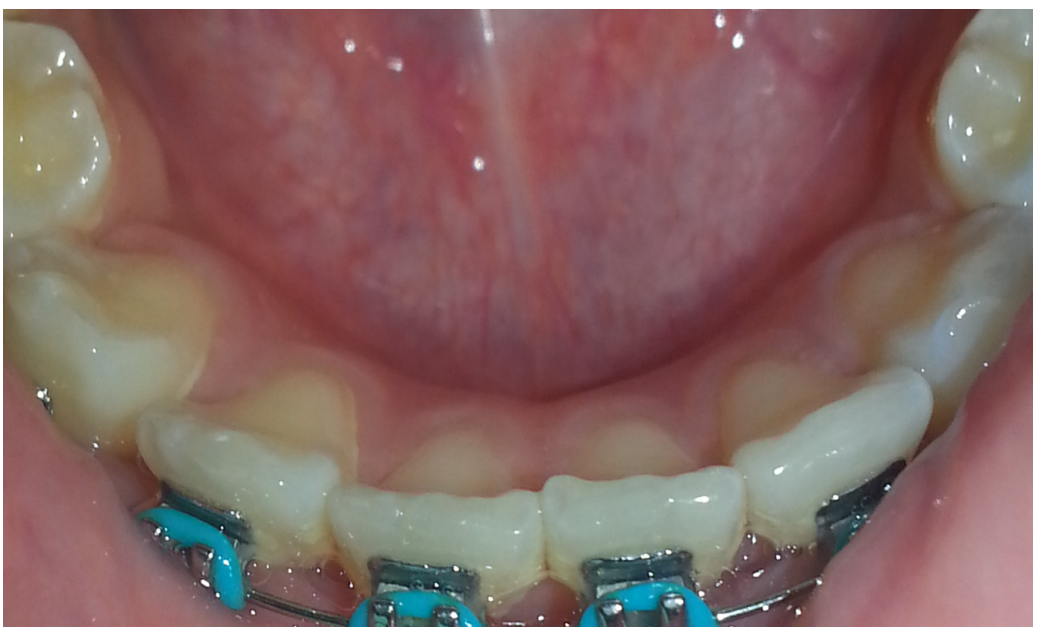

Figure 1A: Intra Oral exam demonstrated no buccal.

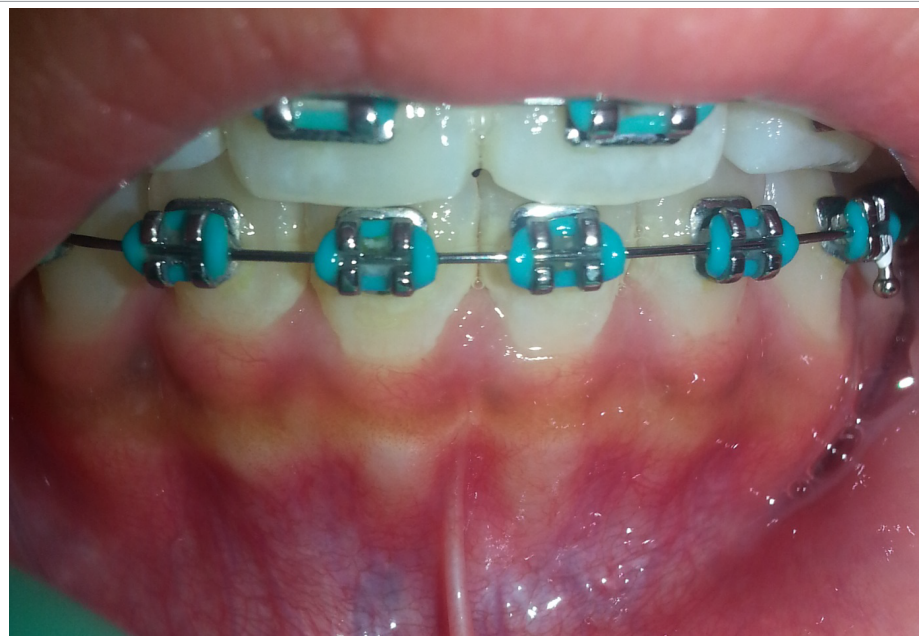

Figure 1B: Intra Oral exam demonstrated lingual cortical expansion

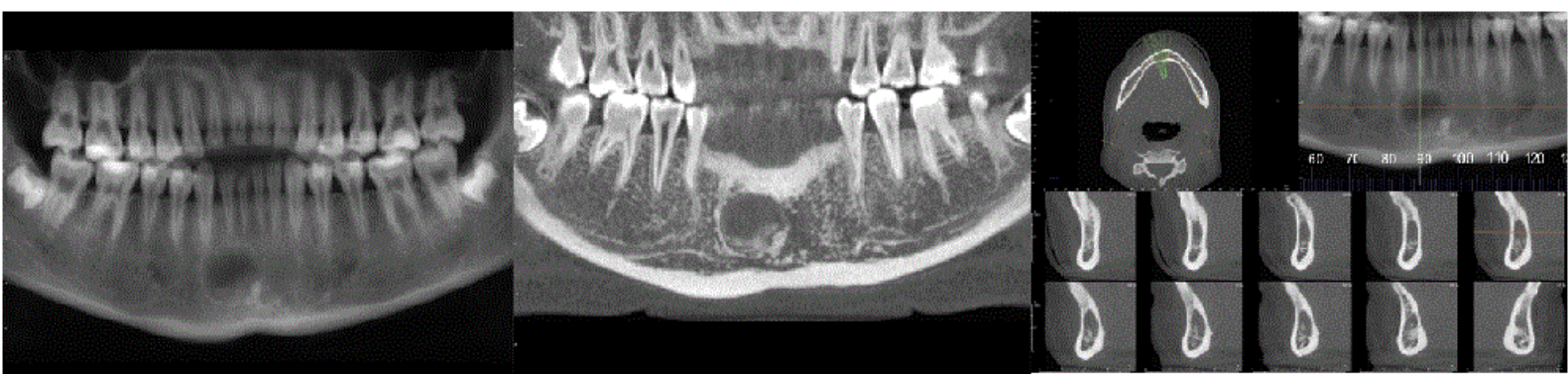

Figure 2: Pre-operative СВСТ shows a well-defined, round, lightly corticated mixed density lesion in the right inferior portion of the anterior mandible. 
Citation: Dano D, Schmidt M, Shosho D, Mecham A (2017) 3D CBCT Superimposition Use in Evaluation of Simple Bone Cyst Lesion Resolution-A Case Report. Dentistry 7: 462. doi:10.4172/2161-1122.1000462

Page 3 of 6

lesion and served as the needle access point for the aspiration performed to determine the content of the cavity.

Aspiration result was positive (Figure $3 \mathrm{~B}$ ) and yield $3 \mathrm{ml}$ of blood like fluid, $5 \times 5 \mathrm{~mm}$ bony window created using \#4 round surgical bur in order to access the bone cavity directly (Figure 3C).

Following a complete curettage of the bony cavity walls, no evidence of any type of tissue lining the cavity. 3/0 chromic gut Sutures used and dressing placed on the chin to support muscles attachment.

Post-operative healing period was uneventful and patient presented for post-operative follow up appointments after 2 weeks, 6, 12, 18, 24 and 30 months.

A 30 month Post-operative CBCT showed complete resolution

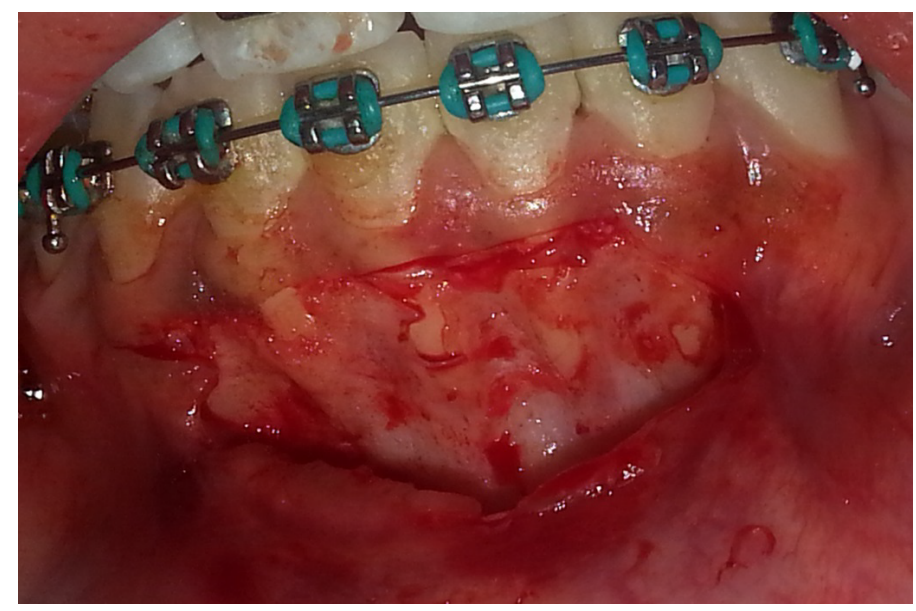

Figure 3A: Operative procedure: Flap design.

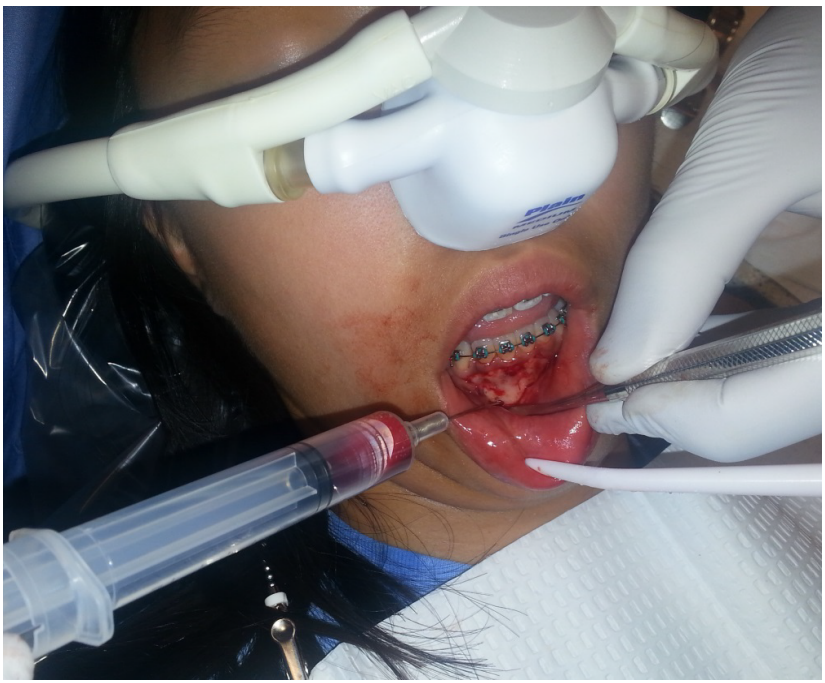

Figure 3B: Operative procedure: aspiration results

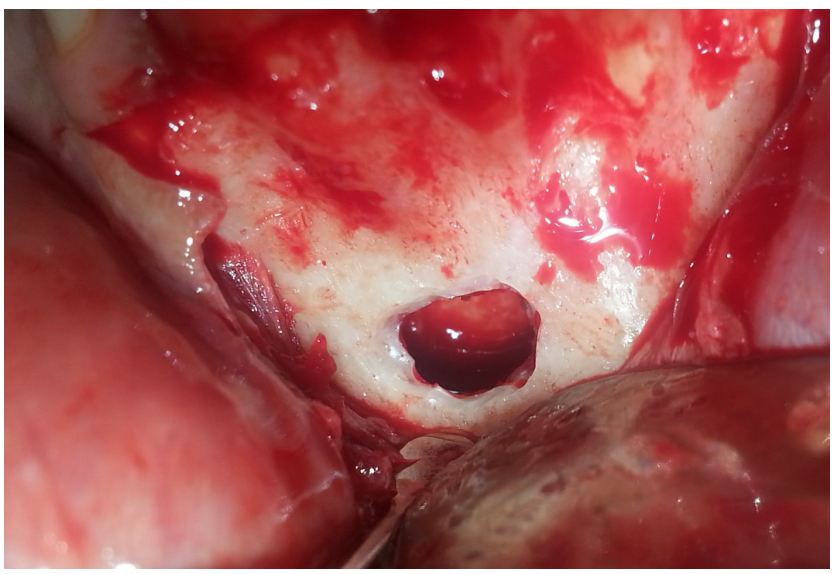

Figure 3C: Operative procedure: Lesion cavity.

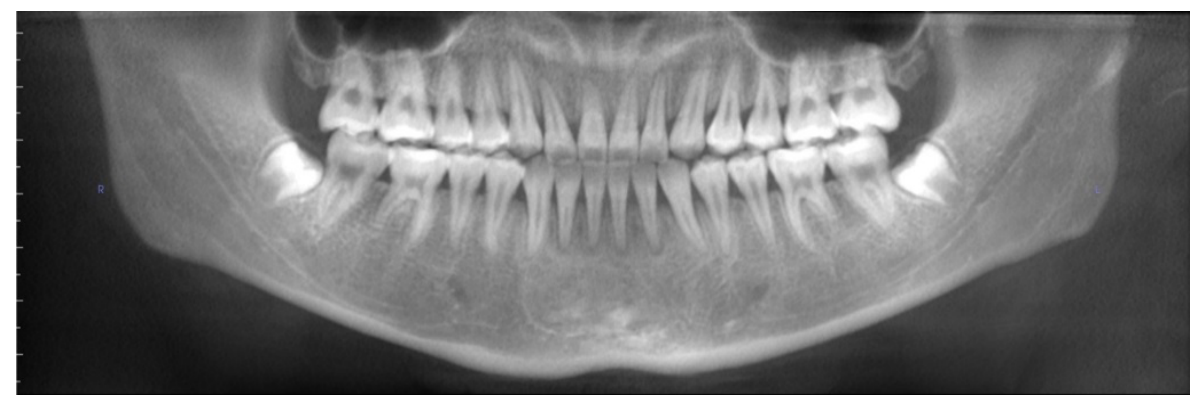

Figure 4A: A 30 month Post-operative CBCT Panoramic Reformat. 
of lesion and bone gain as presented in Figure 4A and clinical exam demonstrated healthy tissue and periodontium (Figure 4B).

\section{Discussion}

The purpose of this case report is to present a unique representation of overlapped diagnostic СBCT slices for a classically presented lesion. The lesion was incidentally detected on a CBCT scan acquired when the patient was 14 years of age. It presented as a well-defined, faintly corticated, round radiolucency in the mandibular right anterior region apical to teeth \#25 through 27 . The lesion was noted to be partially radiolucent, largely hypodense with some ossification in the inferior extent. Slight thinning of the buccal and lingual cortical plates was noted. Differential diagnoses included simple bone cyst, aneurysmal bone cyst, and central giant cell granuloma (Figure 5).

The asymptomatic nature of the simple bone cyst often results in incidental discovery, as described in this particular case. The well circumscribed, unilocular lesion surrounded by bony walls but lacking epithelial lining falls in line with the diagnostic criteria of simple bone cysts as established in 1946 [11]. Presentation of this lesion is suggestive of SBC.

Although SBC's are typically not known to cause calcification, there are existing reports of spontaneous lesion healing. The calcifications at the inferior aspect of this particular lesion may, therefore, have been a

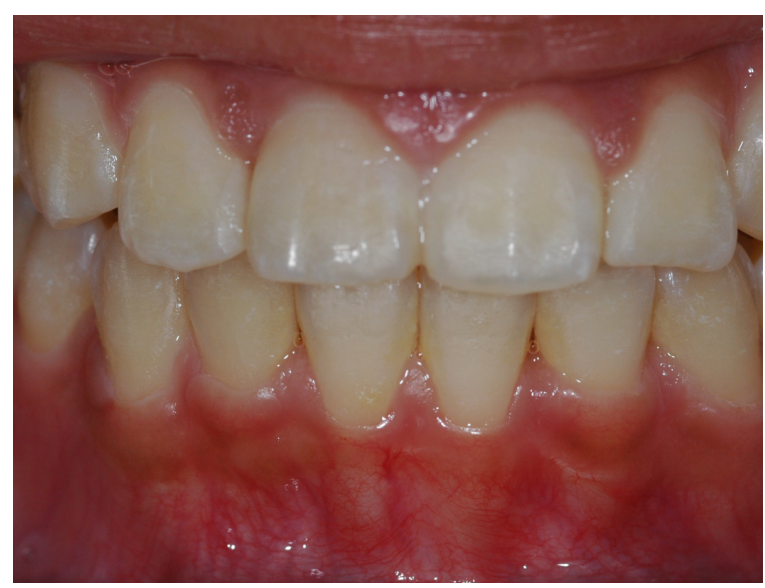

Figure 4B: A 30 month Post-operative CBCT clinical appearance. result of spontaneously healed bone rather than calcification produced by the image itself or secondarily to infection.

Important to note is the lack of bone expansion surrounding the lesion and confirmed vitality of neighboring teeth. Diagnosis of simple bone cyst prior to exploratory curettage is difficult despite the classic presentation of the lesion.

Surgical intervention is, therefore, both helpful in narrowing down the differential diagnoses as well as greatly effective in resolving the lesion.

Regeneration and resolution of this lesion following surgical exploration are in agreement with literature (8) that emphasizes the significance of a) early radiographic detection and b) exploratory curettage as means to stop the lesion from progressing in size or causing any changes in vitality to neighboring teeth.

Bleeding induced by the exploratory curettage supplies fresh blood to the area inducing further osseous regeneration and mesenchymal cell differentiation [10].

In cases where simple exploratory curettage is unsuccessful, injection of lyophilized bone, hydroxyapatite, or Gel-foam have been introduced as therapeutic alternatives $[3,4,9]$.

For our patient, a follow-up CBCT was taken 30 months following the initial evaluation and the surgical procedure. At that time the patient was 17 years old and the two CBCT's were compared. The new CBCT showed a thinner, fainter corticated border and a cloudy mixed appearance of the internal structure (Figures 4-6). The internal structure showed a swirling, cloudy hyperdense appearance, consistent with healing bone formation (Figure 7).

Superimposition Anatomage Invivo software, version 5.4.5, was used for visualization and image formation of the two data sets as well as performing superimposition of the two scans.

To perform superimposition, the preoperative scan was imported over the postoperative scan. The mandibular bone was used to align the two scans as there was discrepancy in the position of the mandible in the two scans. Orthodontic tooth movement was also evident.

During superimposition, voxels from the original scan maintain white hue, while voxels of the imported scan are given a blue-green hue. The best visual representation of bony changes resulted when the 2017 scan was initially opened and the 2014 scan was imported and superimposed as a new volume. This resulted in white bony changes

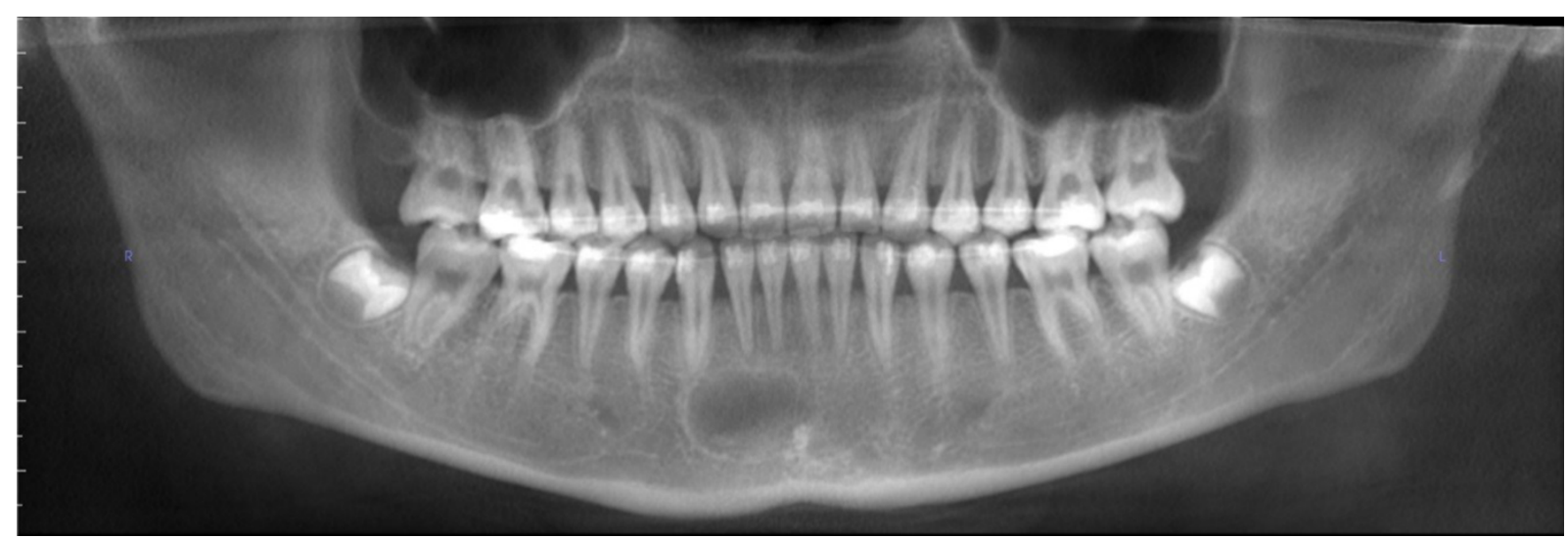

Figure 5: Pre-operative CBCT Panoramic Reformat. 
Citation: Dano D, Schmidt M, Shosho D, Mecham A (2017) 3D CBCT Superimposition Use in Evaluation of Simple Bone Cyst Lesion Resolution-A Case Report. Dentistry 7: 462. doi:10.4172/2161-1122.1000462

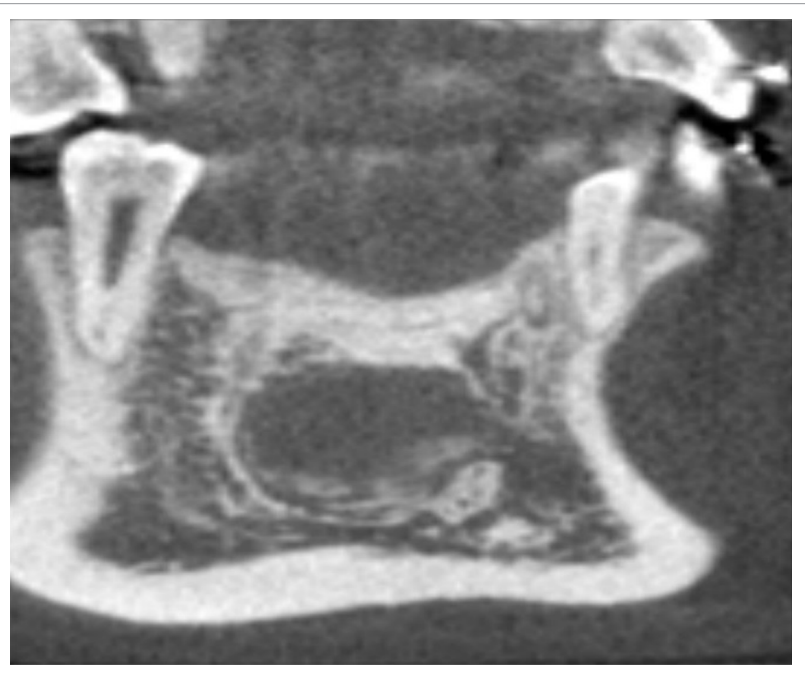

Figure 6A: Preoperative CBCT Coronal section.

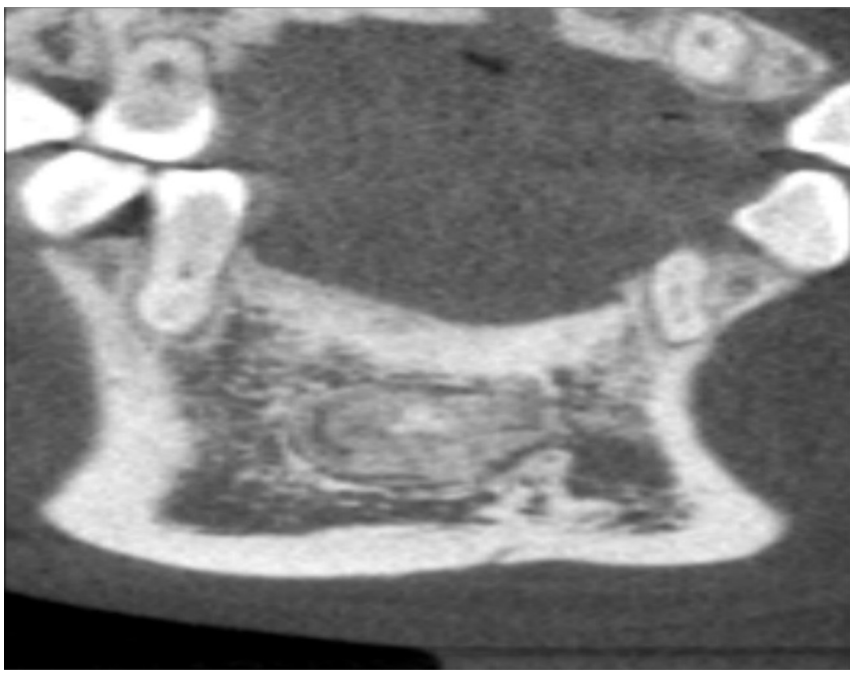

Figure 6B: Preoperative $\mathrm{CBCT}$ postoperative.

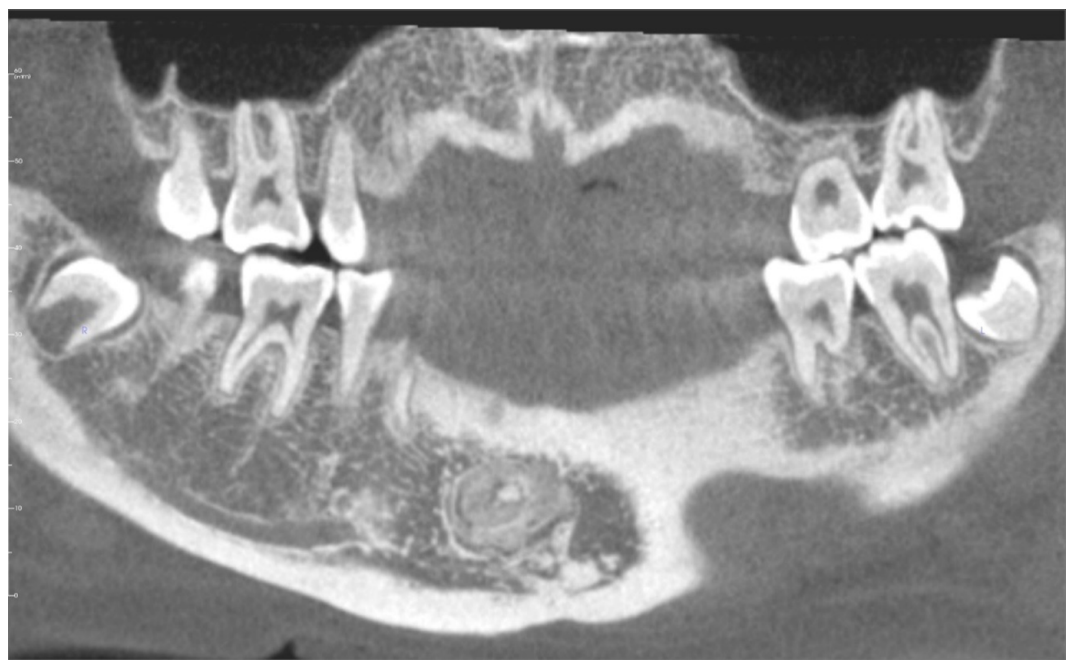

Figure 7: Postoperative curved section demonstrating swirling hyperdense internal appearance within the healed lesion. 
Citation: Dano D, Schmidt M, Shosho D, Mecham A (2017) 3D CBCT Superimposition Use in Evaluation of Simple Bone Cyst Lesion Resolution-A Case Report. Dentistry 7: 462. doi:10.4172/2161-1122.1000462

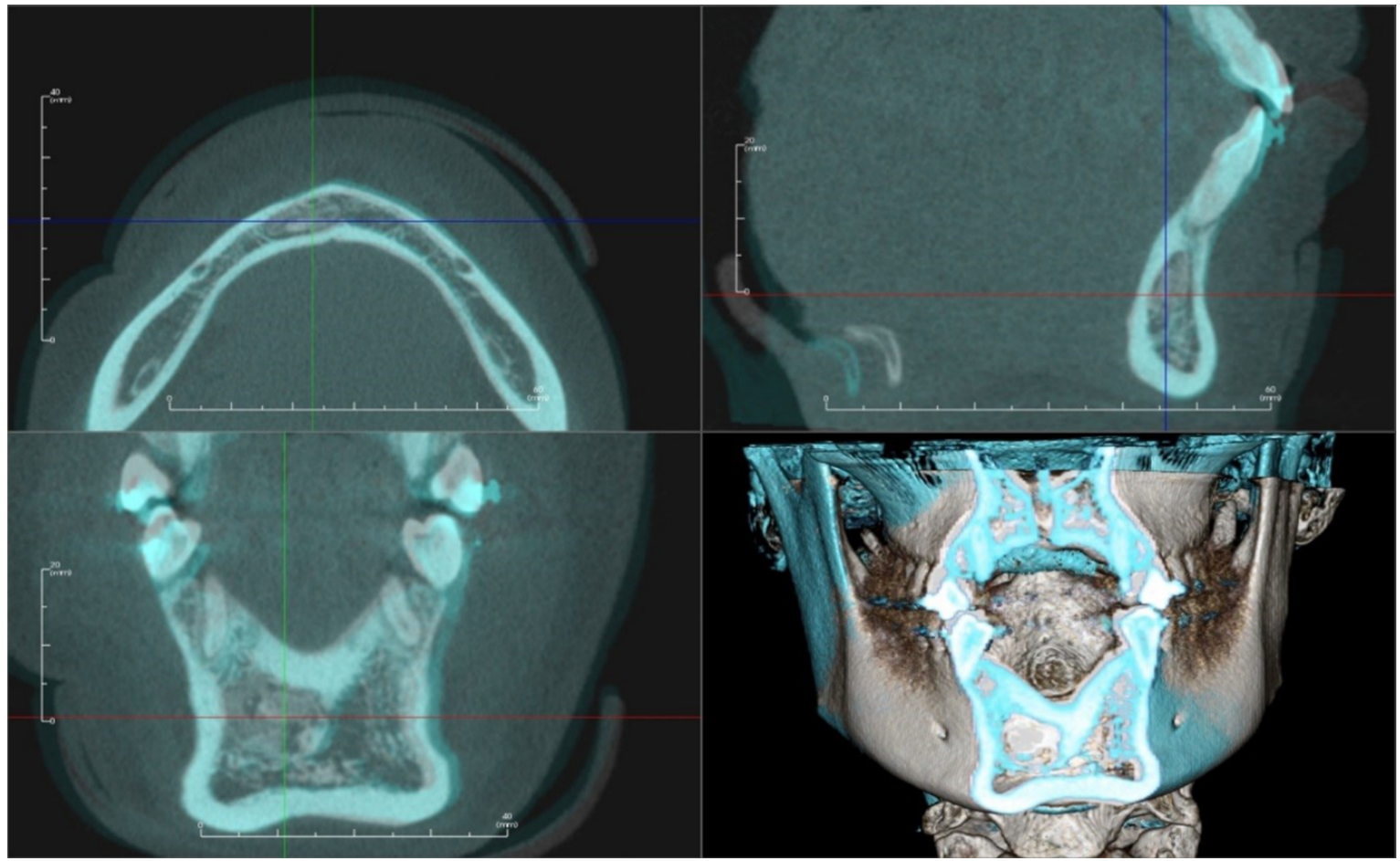

Figure 8: Superimposition: preoperative (blue-green) overlaid on postoperative(white).

between the pre and post-operative scans. White voxels then stand out in contrast to surrounding blue-green voxels, showing where new bone formation took place (Figure 8).

\section{Conclusion}

Superimposition of the CBCT scans depicts progressive osseous regeneration of the unilateral lesion with no evidence of recurrence 30 months later.

Simple bone cysts are known in literature as wholly radiolucent or hypodense lesions that do not cause calcifications. Therefore ossification of a healing lesion could be a confounding radiographic feature. It is important to consider a spontaneously healing simple bone cyst as part of a differential diagnosis when presented with mixed or hyperdense lesions even in the case that the lesion is thought to have arisen de novo.

Conclusive etiology and pathogenesis of simple bone cysts are yet to be met. Keeping this in mind, continued reporting of well-described cases is a critical component to assembling information for further analysis.

\section{References}

1. Beasley JD (1976) Traumatic cyst of the jaws: report of 30 cases. J Am Dent Assoc 92: 145-152.

2. Breen GH, Addante R (1994) A recurrent traumatic bone cyst: report of case. ASDC J Dent Child 61: 141-145.

3. Cortell-Ballester I, Figueiredo R, Berini-Aytes L, Gay-Escoda C (2009) Traumatic bone cyst: a retrospective study of 21 cases. Med Oral Patol Oral Cir Bucal 14: E239-E243.

4. Dellinger TM, Holder R, Livingston HM, Hill WJ (1998) Alternative treatments for a traumatic bone cyst: a longitudinal case report. Quintessence Int 29: 497-502.

5. Discacciati ED, de Faria VM, Garcia NG, Sakai VT, Pereira AA, et al. (2012)
Idiopathic bone cavity: case series involving children and adolescents. J Investig Clin Dent 3: 103-108.

6. Hansen LS, Sapone J, Sproat RC (1974) Traumatic bone cysts of jaws. Ora Surg Oral Med Oral Pathol 37: 899-910.

7. Harnet JC, Lombardi T, Klewansky P, Rieger J, Tempe MH, et al. (2008) Solitary bone cyst of the jaws: a review of the etiopathogenic hypotheses. J Oral Maxillofac Surg 66: 2345-2348.

8. Oliveira DT, Hoshi AT, dos Reis OP (2000) Clinical management of traumatic bone cyst in children: a case report. J Clin Pediatr Dent 24: 107-110.

9. Penarrocha-Diago M, Sanchis-Bielsa JM, Bonet-Marco J, Minguez-Sanz JM (2001) Surgical treatment and follow-up of solitary bone cyst of the mandible:a report of seven cases. Br J Oral Maxillofac Surg 39: 221-223.

10. Precious DS, McFadden LR (1984) Treatment of traumatic bone cyst of mandible by injection of autogeneic blood. Oral Surg Oral Med Oral Pathol 58:137-140.

11. Rushton MA (1946) Solitary bone cysts in the mandible. Br Dent J 81: 37-49.

12. Sapp JP, Stark ML (1990) Self-healing traumatic bone cysts. Oral Surg Oral Med Oral Pathol 69: 597-602.

13. Scholl RJ, Kellett HM, Neumann DP, Lurie AG (1999) Cysts and cystic lesions of the mandible: clinical and radiologic-histopathologic review. Radiographics 19: $1107-1124$

14. Suomalainen A, Apajalahti S, Kuhlefelt M, Hagstrom J (2009) Simple bone cyst: a radiological dilemma. Dentomaxillofac Radiol 38: 174-177.

15. Kumar SLK, Kurien N, Thaha KA (2015) Traumatic Bone Cyst of Mandible. Journal of Maxillofacial and Oral Surgery 14: 466-469.

16. Velez I, Siegel MA, Mintz SM, Rolle R (2010) The relationship between idiopathic bone cavity and orthodontic tooth movement: analysis of 44 cases. Dentomaxillofacial Radiology 39: 162-166.

17. White SC, Pharoah MJ (2014) Oral radiology : principles and interpretation. (7 $7^{\text {Th }}$ Edn) St. Louis, Missouri: Elsevier.

18. Xanthinaki AA, Choupis KI, Tosios K, Pagkalos VA, Papanikolaou SI (2006) Traumatic bone cyst of the mandible of possible iatrogenic origin: a case report and brief review of the literature. Head Face Med 2: 40. 